\title{
Shear strength of bonded concrete-granite joints under constant normal stress conditions
}

\author{
Matthieu Briffaut ${ }^{1, *}$, Bassel El Merabi ${ }^{1}$, Frédéric Dufour ${ }^{1,2}$ and Grégory Coubard ${ }^{3}$ \\ ${ }^{1}$ Univ. Grenoble Alpes, CNRS, Grenoble INP, 3SR, F-38000 Grenoble, France \\ ${ }^{2} \mathrm{Head}$ of the Chair PERENITI (EDF SEPTEN/DTG/CIH) \\ ${ }^{3}$ Electricité De France (EDF-CIH), Bourget-du-Lac, France
}

\begin{abstract}
The shear behaviour of bonded concrete-granite joints under constant normal stress conditions is experimentally investigated in this paper. Concrete was prepared following standard mix used in pre-existing dams in France and poured on granite samples with a natural surface roughness. Before the direct shear tests, the joint surfaces were scanned by a laser profilometer to obtain the 3D morphology features. By analysing the shear test results, no direct correlations were found between the shear strength of bonded joints and classical roughness parameter.
\end{abstract}

\section{Introduction}

The shear strength of the concrete-rock interface is a key factor in assessing the stability against sliding of concrete dams founded on rock [1]. Most of the design codes for dams propose conventional values for the mechanical parameters of the interface (i.e. cohesion and friction angle) depending on the type of the rock foundation ([2], [3]). Several experimental campaigns conducted during the last fifty years have demonstrated that several factors contribute to the shear strength of the dam-foundation interface including the joint roughness ([4], [5], [6], [7], [8]), the normal stress level, the initial bonding between the joint surfaces ([9], [10], [11]), the shear displacement rate and the mechanical properties of the joint surfaces. While several studies have been conducted on frictional joints ([6], [12], [13], [14]), there remains an uncertainty regarding the mechanical behaviour of bonded surfaces [16].

Another major difficulty lies in the quantification of surface roughness. Several methods of analysing surface roughness were adopted in the literature including fractal analysis ([17], [18], [19]), statistical methods ([20], [21], [22]) and Barton's empirical method [23]. Except the method proposed by Grasselli [24], all the conventional techniques to assess roughness values are based on the shape of $2 \mathrm{D}$ profile. This can lead to inaccurate estimates of surface roughness since the joint morphology is strongly variable in space.

The joints production and roughness characterization is described in a first part, the second part is devoted to the presentation of the results of shear test and in the final part an analysis of the results thanks to a upgraded roughness parameter is proposed.

\footnotetext{
* Corresponding author: matthieu.briffaut $@, 3$ sr-grenoble.fr
}

\section{Methodology for the direct shear tests}

\subsection{Tested materials}

The concrete used was chosen based on the formula adopted in pre-existing concrete dams in France (Table 1) with an average compressive strength of $43.4 \mathrm{MPa}$ and a tensile strength of $3.75 \mathrm{MPa}$. The chosen rock was granite since it is commonly found in dam foundations. Its mechanical properties are an average tensile strength of $10.2 \mathrm{MPa}$ and a compressive strength of $133 \mathrm{MPa}$ which is about three times larger than the concrete ones.

Table 1: Concrete formula used for samples preparation

\begin{tabular}{|c|c|}
\hline Component & $\begin{array}{c}\text { Quantity } \\
\text { (kg/m3) }\end{array}$ \\
\hline Cement CEM52.5R & 280 \\
\hline Sand 0/4mm & 650 \\
\hline Sand 0/2mm & 150 \\
\hline Aggregate 11.2/22.4mm & 780 \\
\hline Aggregate 4/11mm & 330 \\
\hline Plasticizer - OPT 203 & 2.80 \\
\hline Water & 157 \\
\hline
\end{tabular}

\subsection{Sample preparation}

In the following experiments, the joint samples are produced with a size of $10 \mathrm{~cm}$ by $10 \mathrm{~cm}$ following a six step approach (Fig. 1; 3 steps for each half box). Granite samples were cut to the dimensions of $10 \mathrm{~cm}$ by $10 \mathrm{~cm}$ and placed in the lower shear box. Concrete is then poured on the granite surface in order to achieve a fully bonded surface and a thin layer of cement paste is applied on the surface of concrete to achieve a smooth 
finish. The assembly is vibrated and left to dry for 24 hours, then, it is turned upside down in order to seal the granite sample in the lower shear box by the use of mortar. As for the upper shear box, a thin layer of cement is applied on the mortar to achieve a smooth finish. Lastly, all the specimen were left to dry for a period of 28 days in ambient temperature.

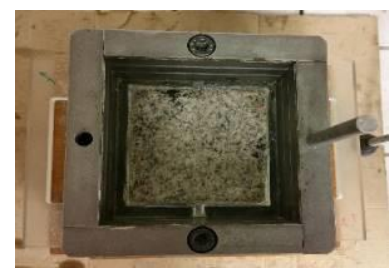

(a)

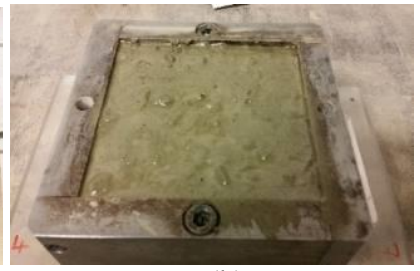

(b)

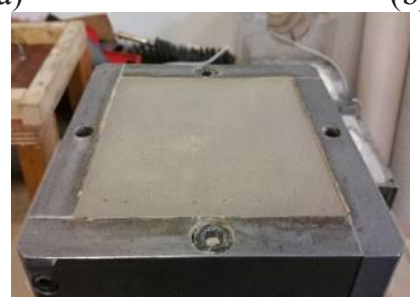

(c)

Fig. 1. a) Preparation of the internal shear boxes: (a) Adjusting the position of the mean plane, (b) Pouring concrete in the upper half-box after humidifying the granite surface, (c) Applying a thin layer of cement to the upper surface of concrete to have a smooth surface texture.

\subsection{Roughness characterization}

The rock joint surface was scanned by a laser profilometer (Fig.2), which is a non-contact measurement system (own development) allowing a 3D digitalisation of the joint surface with high precision. The system consists of a laser sensor mounted on two orthogonal axes allowing displacements parallel to the mean plane of the joint. The laser beam emitted on the joint surface is reflected and then detected by a laser sensor to calculate the distance $Z$ at the measured point with a vertical precision of $0.05 \mathrm{~mm}$. Measurements of the joint morphology are carried out by parallel profiles oriented in the $\mathrm{X}$ direction and offset by increments of displacements along the $\mathrm{Y}$ axis

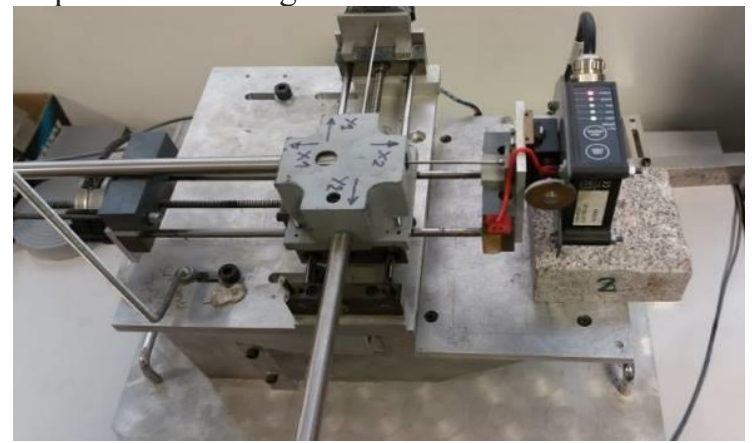

Fig. 2. Laser profilometer

Therefore, three roughness parameters will be calculated to quantify the morphology of the rock joint surface since they are representative of three different aspects of surface morphology: the wavelength $(\lambda)$, the amplitude $\left(R_{t}\right)$ and the angularity $\left(\theta_{2 D^{+}}\right)$.

$$
\left\{\begin{array}{c}
R_{t}=\max \left\{Z_{i}\right\}-\min \left\{Z_{i}\right\} \\
\theta_{2 D}=\frac{1}{N} \sum_{i=1}^{N} \operatorname{Arctan}\left(\frac{Z_{i+1}-Z_{i}}{\Delta x}\right) \\
\lambda, \text { where } \mathrm{z}=a_{i} \cos \left(\frac{2 \pi}{\lambda} \times x\right)+b_{i} \sin \left(\frac{2 \pi}{\lambda} \times x\right)
\end{array}\right.
$$

where $\mathrm{z}$ is the amplitude of the profile and $\mathrm{x}$ is the horizontal position.

\subsection{Shear test device}

The experimental study of the mechanical behaviour of perfectly cohesive joints was carried out by direct shear testing using a high quality experimental device designed and developed in the 3SR lab (Fig. 3). The originality of this device lies in the fact that shearing is not due to the displacement of one of the parts of the joint - either the upper part or the lower part - but to the symmetrical displacements in opposite directions of the upper and lower parts of the sample. This leads to a normal force always centred on the active part of the joint and to a limited rotation of the upper half of the sample

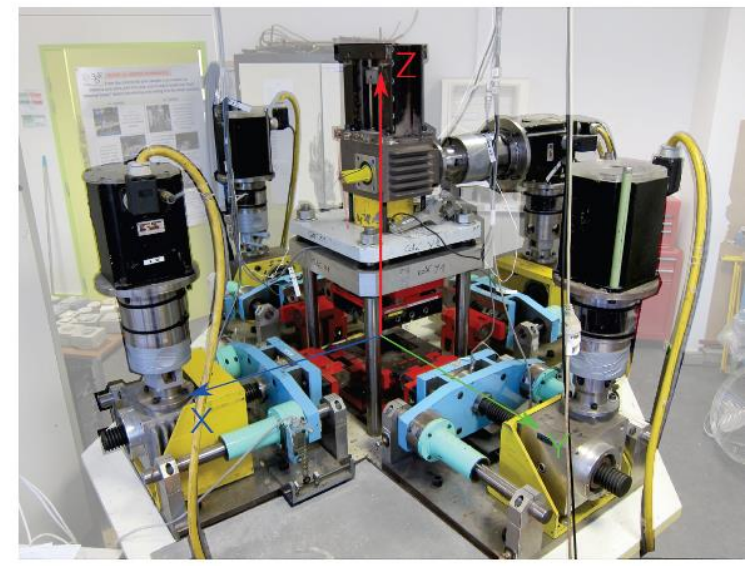

Fig. 3. Overview of the shear device developed by [25]

\section{Direct shear tests results}

The results of the shear tests (constant normal stress) on natural granite samples showed two different shear behaviours based on the applied normal stress. Fig. 4a is a typical shear stress curve for the specimens sheared at a low normal stress of $0.5 \mathrm{MPa}$ presumably with a low surface roughness ("Type I" behaviour). It is characterised by a peak in the shear stress curve followed by a gradual decrease toward a residual value. Fig. $4 \mathrm{~b}$, on the other hand, shows a typical shear behaviour observed for all the specimens sheared under 1 and $1.5 \mathrm{MPa}$ of normal stress and for two of the samples sheared under $0.5 \mathrm{MPa}$ of normal stress with a high surface roughness ("Type II" behaviour). This shear behaviour also exhibited a clear peak in the shear stress curve. The difference was mainly in the post peak phase where a brittle failure is observed for the "Type II" behaviour, accompanied by a sudden decrease in the shear stress. The value of the shear stress then decreases up to a constant residual value. 


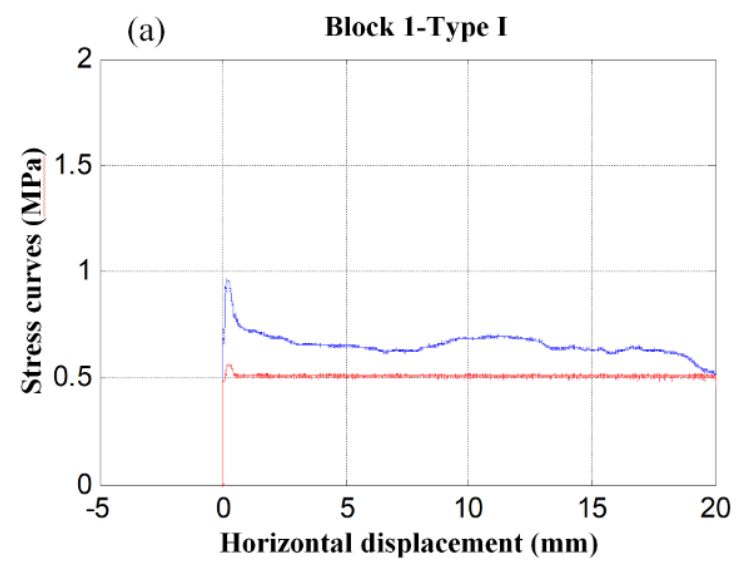

(a)

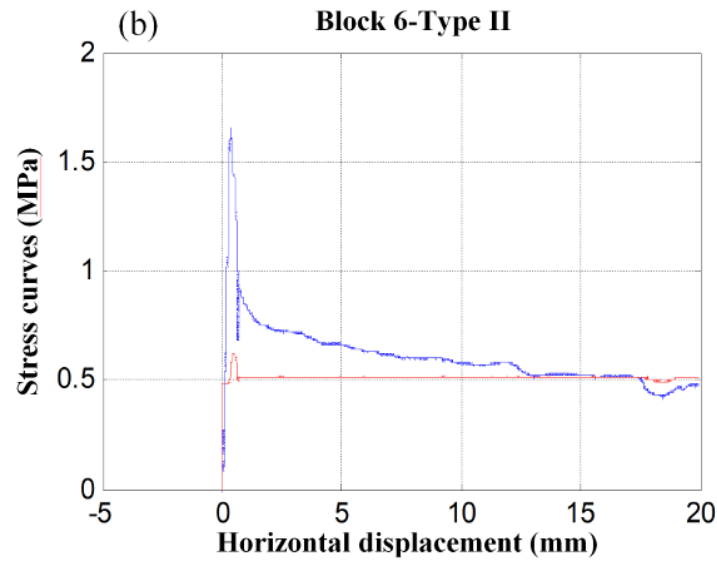

(b)

Fig. 4 The two different shear behaviours observed for the direct shear tests conducted on natural joints with different features, (a) low roughness, (b) high roughness. Shear stress in blue and normal stress in red

It should be noted that the examination of the joint surfaces after the shear tests shows that failure occurred mainly at the concrete-granite contact since the granite surface was intact. Sometimes, small amount of concrete remains glued to the granite block meaning that the rupture is inside the concrete. The distribution of the damaged concrete surfaces was found to vary among the sheared samples according to the applied normal stress. An increase in the applied normal stress was found to increase the proportion of the joint surface where failure occurs in concrete. The table 2 summarises the results of the 15 direct shear tests conducted on natural joint surfaces.

The results of the 15 direct shear tests performed on the natural granite surfaces showed variability in both the peak shear stress and the residual stress values for each level of normal stress. Furthermore, a general increase can be seen in the values of the peak and residual stresses with respect to the normal stress. A linear interpolation performed for the peak shear stress values, gives a peak friction angle of $59^{\circ}$ and an initial cohesion of $0.55 \mathrm{MPa}$. The same interpolation performed for the residual shear stress values gives a residual friction angle of $48^{\circ}$ (see Fig 5.).
Table 2: Main characteristics of the results of the shear tests conducted under three levels of normal stress

\begin{tabular}{|c|c|c|c|c|}
\hline $\begin{array}{c}\text { Speci } \\
\text { men } \\
\text { No. }\end{array}$ & $\begin{array}{c}\text { Normal } \\
\text { stress, } \\
\sigma_{\mathbf{n}} \\
(\mathrm{MPa})\end{array}$ & $\begin{array}{c}\text { Peak } \\
\text { shear } \\
\text { stress, } \\
\tau_{\text {peak }} \\
(\mathrm{MPa})\end{array}$ & $\begin{array}{c}\text { Shear } \\
\text { behaviour } \\
\text { Type }\end{array}$ & $\begin{array}{c}\text { Residual } \\
\text { shear stress, } \\
\tau_{\text {res }}(\mathrm{MPa})\end{array}$ \\
\hline 1 & \multirow{6}{*}{0.5} & 0.97 & \multirow{4}{*}{ I } & 0.62 \\
\hline 2 & & 1.18 & & 0.80 \\
\hline 3 & & 1.24 & & 0.47 \\
\hline 4 & & 1.33 & & 0.62 \\
\hline 5 & & 1.57 & \multirow{11}{*}{ II } & 0.43 \\
\hline 6 & & 1.66 & & 0.49 \\
\hline 7 & \multirow{5}{*}{1} & 2.05 & & 0.95 \\
\hline 8 & & 2.2 & & 1.12 \\
\hline 9 & & 2.25 & & 0.88 \\
\hline 10 & & 2.54 & & 0.9 \\
\hline 11 & & 2.77 & & 1.45 \\
\hline 12 & \multirow{4}{*}{1.5} & 2.7 & & 1.50 \\
\hline 13 & & 2.96 & & 1.74 \\
\hline 14 & & 3.06 & & 1.90 \\
\hline 15 & & 3.13 & & 1.86 \\
\hline
\end{tabular}

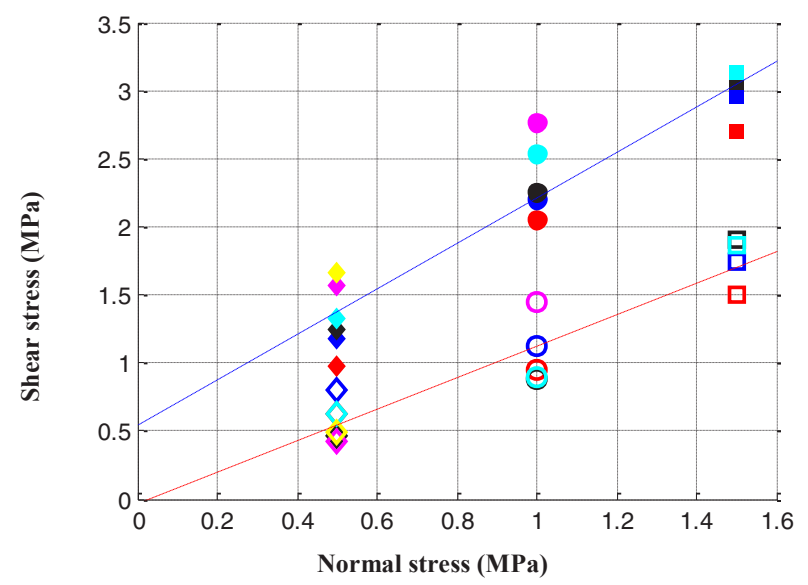

Fig. 5 Mohr-Coulomb criterion plotted for the results of the 15 direct shear tests performed on natural granite surfaces based on the : (Blue) Peak shear stress values, (Red) Residual shear stress values

\section{Peak shear strength correlation with roughness}

In order to characterise the variability in the test results and to find a potential correlation between the shear strength and the surface roughness, the maximum shear 
stress values were compared to different statistical parameters calculated on the joint surfaces. In table 3 linear correlations were calculated between the shear strength and three of the roughness parameters since they are considered representative of three different aspects of surface roughness: $\lambda$ (wavelength), $\mathrm{R}_{\mathrm{t}}$ (amplitude) and $\theta_{2 \mathrm{D}+}$ (angularity).

Table 3: Correlations between the shear strength and the roughness parameters; R stands for linear correlation factor

\begin{tabular}{|c|c|c|c|c|c|}
\hline Block & $\begin{array}{c}\sigma_{\mathrm{n}} \\
(\mathbf{M P a})\end{array}$ & $\begin{array}{c}\tau_{\text {peak }} \\
(\mathrm{MPa})\end{array}$ & $\begin{array}{c}\lambda \\
(\mathrm{mm})\end{array}$ & $\theta_{2 \mathrm{D}}{ }^{+}$ & $\begin{array}{c}R_{t} \\
(\mathbf{m m})\end{array}$ \\
\hline 1 & \multirow{6}{*}{0.5} & 0.97 & 64 & 10.0 & 3.49 \\
\hline 2 & & 1.18 & 65 & 10.6 & 3.71 \\
\hline 3 & & 1.24 & 52 & 14.8 & 5.07 \\
\hline 4 & & 1.33 & 54 & 14.9 & 3.93 \\
\hline 5 & & 1.57 & 65 & 13.5 & 3.57 \\
\hline 6 & & 1.66 & 62 & 14.1 & 4.69 \\
\hline (R) & & & 0.07 & 0.6 & 0.3 \\
\hline 7 & \multirow{5}{*}{1} & 2.05 & 56 & 13.6 & 3.57 \\
\hline 8 & & 2.20 & 63 & 10.0 & 3.49 \\
\hline 9 & & 2.25 & 66 & 13.3 & 4.62 \\
\hline 10 & & 2.54 & 55 & 13.1 & 3.90 \\
\hline 11 & & 2.77 & 68 & 13.3 & 4.44 \\
\hline (R) & & & 0.6 & -0.4 & 0.5 \\
\hline 12 & \multirow{4}{*}{1.5} & 2.70 & 63 & 10.0 & 3.49 \\
\hline 13 & & 2.96 & 65 & 14.6 & 5.24 \\
\hline 14 & & 3.06 & 67 & 14.8 & 4.97 \\
\hline 15 & & 3.13 & 65 & 15.8 & 4.99 \\
\hline (R) & & & 0.07 & -0.4 & -0.6 \\
\hline
\end{tabular}

The comparison of each roughness parameter to the shear strength gives no clear correlation. This was true for all three levels of normal stress. A single roughness parameter $\left(\lambda, \theta_{2 \mathrm{D}+}\right.$ or $\left.\mathrm{R}_{\mathrm{t}}\right)$ was found insufficient to characterise the different shear strength values. For instance, in the case of a sample with triangular asperities, the mean inclination angle is insufficient to characterise the surface roughness since the sample can have different amplitude/wavelength. Consequently, a new roughness parameter is needed in order to quantify the three dimensional surface roughness and to provide a better morphological classification of the granite samples.

\section{Conclusions}

In this research, the shear behaviour of bonded concretegranite joints was investigated by performing a series of direct shear tests on joints with different levels of natural surface roughness and under various normal stresses.

The results of the direct shear tests on natural joints showed two different shear behaviours according to the level of the applied normal stress. Due to the different modes of failure occurring at the joint surface, the characterisation of the shear strength variability observed experimentally by means of a conventional statistical roughness parameter was difficult to achieve. None of the calculated roughness parameters from the literature was sufficient to predict the shear strength results of the bonded natural joints.

Moreover, an examination of the joint surfaces after the shear tests revealed that when the applied normal stress increases different modes of failure is taking over at the joint surface, i.e. shearing of the concrete asperities. Further work is required to better understand the modes of failure occurring at the joint surface when the normal stress is increased and to reach the proposition of a roughness parameter for low levels of normal stress $\left(\sigma_{\mathrm{n}}<1 \mathrm{MPa}\right)$.

\section{References}

1. Y. Ghannat, "Failure modes approach to safety evaluation of dams," in 13th World Conference on Earthquake Engineering, Vancouver, B.C., Canada, 2004.

2. NVE, "Retningslinje for betongdammer," 2005.

3. EPRI, "Uplift pressures, shear strengths and tensile strengths for stability analysis of concrete gravity dams," 1992.

4. Z. Yang and D. Chiang, "An experimental study on the progressive shear behavior of rock joints with tooth shaped asperities," International journal of rock mechanics and mining sciences, 2000.

5. F. Gu, J. Seidel and C. Haberfield, "Direct shear test on sandstone-concrete joints," International journal of geomechanics, vol. 3, 2003.

6. F. Patton, "Multiple modes of shear failure in rock," in 1st ISRM Congress, Lisbon, Portugal, 1966.

7. B. Ladanyi and G. Archambault, "Simulation of the shear behaviour of a jointed rock mass," in 11th symposium on rock mechanics, Berkeley, 1970.

8. M. Plesha, "Constitutive models for rock discontinuities with dilatancy and surface degradation," International journal for numerical and analytical methods in geomechanics, vol. 11, pp. 345-362, 1987.

9. L. Ooi and J. Carter, "Direct shear behavior of concrete-sandstone interfaces," in 6th international conference on rock mechanics, 1987.

10. Z. Moradian, G. Ballivy and P. Rivard, "Application of acoustic emission for monitoring shear behavior of bonded concrete-rock joints under direct shear test," Canadian journal of civil engineering, vol. 39, 
no. 8, pp. 887-896, 2012.

11. M. Gutierrez, "Shear resistance for concrete dams," Trondheim, Norway, 2013.

12. B. Ladanyi and G. Archambault, "Shear strength and deformability of filled indented joints," in Conference on the geotechnics of structurally complex foundations, Capri, 1971.

13. N. Barton and V. Choubey, "The shear strength of rock joints in theory and practice," Rock mechanics, vol. 10, pp. 1-54, 1977.

14. G. Grasselli, "Shear strength of rock joints based on quantified surface description," Lausanne, 2001.

15. S. Bandis, A. Lumsden and N. Barton, "Experimental studies of scale effects on the shear behaviour of rock joints," International journal of rock mechanics and mining sciences, vol. 18, no. 1, pp. 1-21, 1981.

16. D. Saiang, L. Malmgren and E. Nordlund, "Laboratory tests on shotcrete-rock joints in direct shear, tension and compression," Rock mechanics and rock engineering, pp. 275-297, 2005.

17. P. Kulatilake, g. Shou, T. Huang and R. Morgan, "New peak shear strength criteria for anisotropic rock joints," International journal of rock mechanics and mining sciences, vol. 32, no. 7, pp. 673-697, 1995.

18. J. Muralha, "Fractal dimension of joint roughness surfaces," in Fractured and jointed rock masses, Rotterdam, 1995.

19. N. Odling, "Natural fracture profiles, fractal dimension and joint roughness coefficients," Rock mechanics and rock engineering, vol. 36, pp. 135-153, 1994.

20. R. Tse and D. Cruden, "Estimating joint roughness coefficients," International journal of rock mechanics and mining sciences and geomechanics abstracts, vol. 16, pp. 303-307, 1979.

21. X. Yu and B. Vayssade, "Joint profiles and their roughness parameters," International journal of rock mechanics and mining sciences and geomechancis abstracts, vol. 28, pp. 333336, 1991.

22. M. Reeves, "Rock surface roughness and frictional strength," International journal of rock mechanics and mining sciences, vol. 22, no. 6, pp. 429-442, 1985.

23. ISRM, "Suggested methods for the quantitative description of discontinuities in rock masses," International journal of rock mechanics and mining sciences and geomechanics abstracts, pp. 319-368, 1978.
24. G. Grasselli, J. Wirth and P. Egger, "Quantitaive three-dimensional description of a rough surface and parameter evolution with shearing," International journal of rock mechanics and mining sciences, vol. 39, pp. 789-800, 2002.

25. M. Boulon, "A 3D direct shear device for testing the mechanical behaviour and the hydraulic conductivity of rock joints," in Mechanics of jointed and faulted rock, Vienna, 1995. 